\title{
Language Skills of Young Children With Unilateral Cleft Lip and Palate Following Infant Orthopedics: A Randomized Clinical Trial
}

Emmy M. Konst, Ph.D.

Toni RietVeld, Ph.D.

Herman F.M. Peters, Ph.D.

Anne Marie KulJPers-Jagtman, D.D.S., Ph.D.

\begin{abstract}
Objective: To investigate the effects of infant orthopedics (IO) on the language skills of children with complete unilateral cleft lip and palate (UCLP).

Design: In a prospective randomized clinical trial (Dutchcleft), two groups of children with complete UCLP were followed up longitudinally: one group was treated with IO based on a modified Zurich approach in the first year of life (IO group); the other group did not receive this treatment (non-IO group). At the ages of $2,2 \frac{1}{2}, 3$, and 6 years, language development was evaluated in 12 children (six 10 and six non-IO). Receptive language skills were assessed using the Reynell test. Expressive language skills of the toddlers were evaluated by calculating mean length of utterance (MLU) and mean length of longest utterances (MLLU); in the 6-year-olds, the expressive language skills were measured using standardized Dutch language tests.

Patients: The participants had complete UCLP without soft tissue bands or other malformations.

Results: IO did not affect the receptive language skills. However, the expressive language measures MLU and MLLU were influenced by IO. At age $2 \frac{1}{2}$ and 3 years, the 10 group produced longer utterances than the non-IO group. In the follow-up, the difference in expressive language between the two groups was no longer significant.

Conclusions: Children treated with 10 during their first year of life produced longer sentences than non-IO children at the ages of $2^{1 / 2}$ and 3 years. At 6 years of age, both groups presented similar expressive language skills. Hence, IO treatment did not have long-lasting effects on language development.
\end{abstract}

KEY WORDS: cleft lip and palate, infant orthopedics, language development, randomized prospective clinical trial

Infant orthopedics (IO) is used by many centers worldwide in the comprehensive care for children with cleft lip and palate. Several reports in the literature claim that this treatment has a positive impact on speech and language development (Stuffins, 1981; Hotz et al., 1986; Gnoinski, 1990; Gruber, 1990). How-

Dr. Konst is a Speech Language Pathologist and Dr. Kuijpers-Jagtman is Professor of Orthodontics, Department of Orthodontics and Oral Biology, and Dr. Peters is Associate Professor of Speech Pathology, Department of Voice and Speech Pathology, University Medical Center Sint Radboud, University of Nijmegen, the Netherlands. Dr. Rietveld is Associate Professor of Phonetics, Department of Language and Speech, University of Nijmegen, the Netherlands.

This research was supported by a grant from the National Health Insurance Board of the Netherlands. The research is part of the Dutch intercenter study (called Dutchcleft) into the effects of infant orthopedic treatment in complete UCLP, carried out in the Cleft Palate Center of the University of Nijmegen in close collaboration with the Cleft Palate Centers of the Free University of Amsterdam and the Erasmus University of Rotterdam (coordinating orthodontists: A.M. Kuijpers-Jagtman and B. Prahl-Andersen).

Submitted August 2001; Accepted September 2002.

Address correspondence to: Emmy M. Konst, Department of Orthodontics and Oral Biology, University of Nijmegen, P.O. Box 9101, 6500 HB Nijmegen, the Netherlands. E-mail e.konst@dent.umcn.nl. ever, these reports are largely anecdotal. Results of a prospective randomized clinical trial on the effects of IO (called Dutchcleft) have shown that IO treatment indeed relates to better speech development (Konst et al., 1999, 2000, 2002). Because the development of speech and language are closely interrelated, the question arises whether IO also may affect language development.

It is often indicated in the literature that children with cleft palate are at risk for language delay. Early language delays in children with cleft lip and palate (CLP) were described by Jocelyn et al. (1996), who found statistically significant differences in both receptive and expressive abilities between children with CLP and noncleft peers at the age of 12 months. Neiman and Savage (1997) did not find expressive language delays in children at this age. They reported that toddlers with cleft palate did not exhibit at-risk or delayed expressive language development until 36 months of age. For all other age groups $(5,13$, and 25 months) in their investigation, the development of expressive language was within the normal range. A delay in language skills in children with cleft (lip 
and) palate was also reported by Eliason and Richman (1990), who showed that 5- and 6-year-old children with cleft (lip and) palate had poorer verbal mediation skills, compared with the normative sample.

Language or learning disabilities in children with cleft (lip and) palate may persist in school age. Broder et al. (1998) demonstrated that school-aged children (ranging in age from 6 to 18 years) with cleft (lip and) palate had a disproportionately high incidence of learning disabilities and grade retention and that their school achievements were below average. Richman and Eliason (1984) showed persistent language disabilities in children with cleft palate only (CPO). They concluded that school-aged children ranging in age from 8 to 13 years with CPO exhibited significantly lower performances on language association and auditory short-term memory tasks as well as significantly lower reading comprehension than children with CLP.

In contrast, other studies have not demonstrated a delay in language performance in children with cleft (lip and) palate in comparison with normative samples. Broen et al. (1998) compared the early cognitive and linguistic development of toddlers with cleft palate with that of noncleft peers. Although small but statistically significant differences were found, linguistic and cognitive performance in the children with cleft were well within normal limits. Similarly, Chapman et al. (1998) did not find any significant group differences in conversational skills between children with unilateral cleft lip and palate (UCLP) and their noncleft peers. When the profiles of individual children were examined, however, $50 \%$ of the preschool children with UCLP appeared to exhibit low assertive conversational participation.

Although many studies indicate a language delay in children with cleft palate, the etiology of the language delay is not well understood. It has been suggested that early hearing loss may account for the language disabilities in children with clefts. These children are prone to middle ear effusion, which is often accompanied by mild to moderate hearing loss (Broen et al., 1996). Some studies have reported a relation between hearing loss associated with frequent otitis media with effusion (OME) during the first years of life and lower scores on language measures (Feagans et al., 1987; Friel-Patti and Finitzo, 1990; Roberts et al., 1995; Jocelyn et al., 1996; Shriberg et al., 2000b). Other investigations have not demonstrated such an association between OME and language development (Roberts et al., 1991; Gravel and Wallace, 1992; Paul et al., 1993).

The prospective study performed by Roberts et al. (1995) showed that hearing loss associated with OME was indirectly associated with receptive and expressive language skills and cognitive development mediated by less responsive caregivers. Shriberg et al. (2000b) concluded that there was an increased risk of lower speech-language outcomes at 3 years of age in children with OME and associated depressed hearing levels at 12 to 18 months of age. In their retrospective study, Shriberg et al. (2000a) could find support for the association between increased risk of subclinical or clinical speech disorder in children with early recurrent OME in only one of two demograph- ically controlled samples of children. The researchers emphasized that the relationship between early recurrent OME and a later speech disorder can be explained only by a multifactorial model in which otological, audiological, child, and environmental factors are included.

Some authors state that language delays in children with cleft palate may be genetically determined and mediated by dysfunction in auditory short-term memory (Richman and Eliason, 1984; Čeponienė et al., 1999). Richman and Eliason (1984) showed that a group of children with CPO performed significantly worse on language association and auditory shortterm memory tasks than children with CLP. The investigation by Čeponienė et al. (1999) in which cortical event-related potentials specific to the auditory modality were measured also suggests that dysfunction of auditory short-term memory contributes to the language and learning deficits in children with oral clefts. Auditory short-term memory is one of the components in central cognitive models of language acquisition and perception, and proper functioning of this memory buffer is crucial for normal language development in young children. The authors stated that there is a strong possibility that both the cleft and central nervous system dysfunction are genetically determined. Some processes leading to tissue formation, like the neural cell adhesion molecule (NCAM), are extensively involved in both facial and brain tissue formation. During the development of the face, NCAM plays an important role in the fusion of lip and palatal shelves. In the brain, it participates in the establishment of proper synaptic connections and regulation of neurotransmitter levels.

A third possible cause for language delay in children with cleft palate is found in interaction patterns between these children and their parents (Wasserman et al., 1988). Young children with cleft palate have been shown to exhibit limited abilities regarding social-communicative or vocal behaviors, and the mother may be unable to respond appropriately to the child's efforts to communicate. Chapman and Hardin (1991) investigated the language input of mothers in interactions with their young children. They compared mothers of children with CLP with mothers of noncleft children and concluded that there were more similarities than differences between the two groups of mothers with respect to maternal language characteristics. In contrast, Wasserman et al. (1988) did find consistent different interaction patterns when comparing mothers and their children with speech-related anomalies with controls. Their results suggest that the differences in maternal behavior may be a response to the child's language delay. Broen et al. (1998) endorsed the notion that children with better, more intelligible, age-appropriate speech may receive more accurate feedback. They speculated that language learning is aided by the ability to produce intelligible, age-appropriate speech.

The assumption that the child's language development is related to the ability to produce intelligible, age-appropriate speech is also the basis for the hypothesis in the study that is reported in this article. We investigated the language acquisition in a group of 12 children with complete UCLP. The children all participated in the Dutchcleft clinical trial studying the 
effects of IO. Earlier publications on the results of the Dutchcleft clinical trial have shown that IO positively affects speech development (Konst et al., 1999, 2000, 2002). In concurrence with the assumption that better speech aids the child's language development, it was hypothesized that IO will also affect expressive language development through mediation of better speech.

\section{SubJects AND Methods}

\section{Experimental Design, Eligibility, and Treatment Allocation}

The experimental design was a prospective two-arm randomized, controlled clinical trial in three participating university cleft palate centers in the Netherlands: Nijmegen, Amsterdam, and Rotterdam. The local Ethical Committees approved the study protocol. The patient inclusion criteria were: complete UCLP, infants born at term, both parents Caucasian and fluent in the Dutch language, and trial entrance within 2 weeks after birth. Patients were excluded if other congenital malformations (except for syndactyly) or soft tissue bands were present.

Parents of eligible infants were informed about the trial and written consent obtained. A child entered the trial preferably within 2 weeks after birth and was assigned to one of two groups by means of a computerized balanced allocation procedure. Patients were allocated based on birth weight $(<3300$ $\mathrm{g}$ or $\geq 3300 \mathrm{~g})$ and alveolar cleft width $(<8 \mathrm{~mm}$, between 8 and $12 \mathrm{~mm}$, or $\geq 12 \mathrm{~mm}$ ). One of the groups (IO) received IO in the first year of life and the other group (non-IO) did not. A detailed description of the procedure is provided by Prahl et al. (2001).

\section{Treatment Protocol}

To standardize treatment, all specialists participated in consensus meetings. IO treatment started within 2 weeks after birth and was performed by means of passive plates (modified Zurich approach). The plate has a small extension into the cleft nose, covers the palate and the alveolar ridges, and obturates the cleft in the hard and soft palate (for a detailed description of the technique, see Prahl et al., 2001). The plate was worn 24 hours a day until soft palate closure at 12 months of age. The mean duration of IO in the participants was 59 weeks. One child used the plate for 78 weeks because of feeding problems. Apart from IO treatment, all interventions were the same in both groups. Lip surgery was performed at 18 weeks using the Millard technique. The soft palate was closed at 12 months of age (modified Von Langenbeck procedure). In this treatment protocol, the hard palate was left unrepaired until approximately 9 years of age. Only in cases when speech development was very unsatisfactory did children receive a plate after soft palate closure to obturate the hard palate. None of the participants described in this article received such a hard palate obturator. None of the children in this patient group were referred for speech therapy until the age of 3 years. After that age, however, all children received speech-language treatment for a period of time.

\section{Participants}

In total, 54 infants (41 boys, 13 girls) entered the full trial, 27 in each group. A description of the sample characteristics was provided by Prahl et al. (2001). Because of the prospective nature of the study, the sample size was smaller in the older age groups. Therefore, the data in this report are derived from 12 children (six IO and six non-IO) who were evaluated for speech and language development at 2, 21/2, and 3 years of age. Eleven of these children (six IO and five non-IO) were also seen in a follow-up at 6 years. None of the children had been diagnosed as having cognitive or neurological impairment. Of the 12 children, five came from families with low socioeconomic status (SES), five came from middle-class families, and two families had a high SES based on the classification of professional levels by Van Westerlaak et al. (1975).

\section{Data Acquisition}

The data were collected and analyzed by researchers who were not involved in the treatment of the patients. All of the data were collected in the child's home environment. To assess expressive language skills, a sample of spontaneous speech was recorded using high-quality audio equipment (Sony TCDD7 DAT Walkman [Sony, Tokyo, Japan] with a Sennheiser MD421U-4 dynamic microphone [Sennheiser, Wedemark, Germany]). The recordings were made while the child was playing with one of the researchers. Age-appropriate toys were used for eliciting speech. It was ensured that each conversation sample that was recorded contained at least 100 well-recorded utterances and that it was representative of the child's speech according to the parent.

\section{Receptive Language Skills}

Receptive language skills were assessed with the Reynell Developmental Language Scales Dutch Version (Schaerlaekens and van Ommeslaeghe, 1993). This test has been standardized for the Dutch population, which means that individual scores can be compared with standardized scores. The test was administered at the ages of $2,2 \frac{1}{2}$, and 3 years. The receptive language skill of a child was judged to be normal if the raw score on the Reynell Developmental Language Scales was within $1 \mathrm{SD}$ of the test norm for the child's chronological age. If the raw score was between 1 and 2 SD below the test norm, the development of receptive language was judged to be at risk, and if the raw score was more than two SD below the norm, receptive language was judged to be delayed.

\section{Expressive Language Skills}

Expressive language skills of the children aged 2 to 3 years could not be assessed using standardized tests because there 
TABLE 1 Hearing Thresholds and Presence of Middle Ear Infections for Subjects at 2, 21/2, and 3 Years of Age*

\begin{tabular}{|c|c|c|c|c|c|c|}
\hline \multirow[b]{2}{*}{ Age } & \multicolumn{3}{|c|}{ Middle Ear Infections } & \multicolumn{3}{|c|}{ Hearing Threshold } \\
\hline & None & Some & Frequent & Normal & $25-40 d B$ & $>40 \mathrm{~dB}$ \\
\hline \multicolumn{7}{|l|}{$2 \mathrm{y}$} \\
\hline IO & 1 & 3 & 2 & 4 & 1 & 1 \\
\hline Non-IO & 1 & 3 & 2 & 4 & 0 & 2 \\
\hline \multicolumn{7}{|l|}{$2 \frac{1}{2} 2 y$} \\
\hline IO & 1 & 5 & 0 & 4 & 1 & 1 \\
\hline Non-IO & 0 & 6 & 0 & 4 & 2 & 0 \\
\hline \multicolumn{7}{|l|}{$3 \mathrm{y}$} \\
\hline IO & 1 & 5 & 0 & 3 & 1 & 2 \\
\hline Non-IO & 0 & 6 & 0 & 4 & 1 & 1 \\
\hline
\end{tabular}

$* \mathrm{IO}=$ infant orthopedics.

were no such tests available for the Dutch language at the time of the evaluation. Therefore, two quantitative language measures, MLU (mean length of utterance) and MLLU (mean length of longest utterance), both defined in number of words, were determined on the basis of the recorded conversation sample. These measures are regarded as suitable indexes of global morphosyntactic development in young children (Brown, 1973; Beheydt, 1983; Wells, 1985). The MLU and MLLU were calculated from the conversation sample that was transcribed using the International Phonetic Alphabet first. In addition, MLU was calculated in number of words using 50 utterances per child. The utterances had been produced spontaneously or had been elicited by means of open questions.

The expressive language skills in the follow-up at 6 years were measured using standardized tests. The expressive vocabulary was assessed using a subtest of the Dutch language tests for children (Van Bon, 1982). This subtest is standardized for Dutch children aged 4 to 8 years. The raw scores on the test for expressive vocabulary were transformed into percentile scores using the test norms. Performance on the test was judged to be normal if the child obtained a percentile score within $1 \mathrm{SD}$ of the test norm. The development of expressive vocabulary was judged to be at risk if the score was between 1 and 2 SD below the test norm, and if the score was more than 2 SD below the norm, the expressive vocabulary was judged to be delayed.

Expressive syntactic skills were evaluated by means of the subtest sentence development (Zinsontwikkeling) from the Schlichting test for language production (Schlichting et al., 1995). This subtest is standardized for Dutch children aged 1.9 to 6.3 years. To compare the individual raw scores on the test, these scores were transformed into percentile scores with the help of the test manual. The interpretation of the percentile score was conducted as described above for the vocabulary test.

\section{Hearing Status of the Subjects}

If the two groups in this trial were found to differ from each other in occurrence of middle ear problems and hearing loss,
TABLE 2 The Mean Raw Scores and SD on the Dutch Version of the Reynell Developmental Language Scales at $2 \frac{1}{2}$ and 3 Years*

\begin{tabular}{lccccc}
\hline & \multicolumn{2}{c}{ Age $2 \frac{1}{2} y$} & & \multicolumn{2}{c}{ Age $3 y$} \\
\cline { 2 - 3 } \cline { 5 - 6 } & Mean & SD & & Mean & SD \\
\hline IO & $28.4(\mathrm{n}=5)$ & 6.6 & & $36.5(\mathrm{n}=6)$ & 7.7 \\
Non-IO & $27.7(\mathrm{n}=6)$ & 8.6 & & $37.7(\mathrm{n}=6)$ & 8.0 \\
\hline * IO = infant orthopedics. & & &
\end{tabular}

it would not be clear whether differences in language acquisition could be attributed to IO, impaired hearing, or both. To rule out a difference in middle ear problems and hearing loss between the two groups, the hearing thresholds and middle ear condition of the subjects were evaluated at 2, 21/2, and 3 years by the ear, nose, and throat (ENT) specialist of the cleft palate team. Hearing levels were obtained by free-field audiometry in a sound-controlled chamber or by means of brainstemevoked response audiometry. Hearing thresholds of up to 25 $\mathrm{dB}$ were considered to be normal. The middle ear condition was evaluated by means of otoscopy or by tympanometry. Data on the occurrence of otitis media were also obtained by means of parent report.

\section{Statistical Analysis}

Statistical analysis was performed by means of analysis of variance (ANOVA) with repeated measures, multivariate analysis of variance (MANOVA) simple main effects analysis, and Student's $t$ tests. The applied statistics are also discussed in the Results section.

\section{RESULTS}

\section{Hearing Status}

The hearing thresholds and middle ear problems, if any were present, are presented in Table 1. This table shows that the two cleft groups did not show gross differences in the prevalence of middle ear problems and hearing loss. In the first 3 years of life, most of the subjects had experienced middle ear infections and hearing loss. However, at the time of testing, most children had normal hearing. Because there were no gross differences between the two groups, it was cautiously assumed that the possible negative influence of hearing problems on language development was similar for both groups.

\section{Receptive Language Skills of 2- to 3-Year-Old Children}

The mean scores on the test for receptive language skills by group are presented in Table 2. The 2-year-olds in this study could not be tested reliably with the receptive language test. Reliable data on receptive language skills were available only for the $2 \frac{1}{2}$ - and 3 -year-olds. At age $2 \frac{1}{2}$ years, one subject in the IO group could not be tested reliably. The results for the remaining 11 children showed that the receptive language de- 
TABLE 3 Means (and SD) of MLU and MLLU at Age 2, 21/2, and 3 y for Six Children with IO and Six Children Without IO*

\begin{tabular}{|c|c|c|c|c|c|c|}
\hline & \multicolumn{2}{|c|}{ Age $2 y$} & \multicolumn{2}{|c|}{ Age $21 / 2 y$} & \multicolumn{2}{|c|}{ Age $3 y$} \\
\hline & $I O$ & Non-IO & $I O$ & Non-IO & $I O$ & Non-IO \\
\hline MLU in number of words & $1.47(0.57)$ & $1.08(0.20)$ & $2.09(0.44)$ & $1.48(0.46)$ & $3.21(0.62)$ & $1.97(0.62)$ \\
\hline MLLU in number of words & $2.13(1.11)$ & $1.23(0.57)$ & $3.65(0.94)$ & $2.08(1.02)$ & $4.92(0.81)$ & $2.68(1.14)$ \\
\hline
\end{tabular}

$* \mathrm{IO}=$ infant orthopedics; MLU = mean length of utterance; MLLU = mean length of longest utterance.

velopment of one child in each group was at risk. All other children (four IO and five non-IO) scored within the normal range.

At 3 years of age, all subjects (six IO and six non-IO) could be tested reliably. Their receptive language skills were within the normal range except for one child in the IO group and one in the non-IO group, both of whom obtained at-risk scores.

An ANOVA with repeated measures with "time of observation" as within-subject factor and "IO treatment" as between-subject factor was performed on the data from the 11 children (five IO and six non-IO) who were tested in both age groups. In this analysis, only the time factor was statistically significant $\left(\mathrm{F}_{1,9}=21.44 ; p=.001\right)$. It showed that the raw score on the receptive language test increased with age in both treatment groups. Treatment with IO did not influence this pattern (factor IO: $\mathrm{F}_{1,9}=.02 ; p=.88$; interaction between IO and time: $\left.\mathrm{F}_{1,9}=.00 ; p=.96\right)$.

\section{Expressive Language Skills of 2- to 3-Year-Old Children}

MLU and MLLU were calculated in number of words using 50 utterances per child extracted from the spontaneous speech sample. Seven 2-year-old children (three IO and four non-IO) failed to produce enough meaningful utterances to calculate MLU and MLLU. Because these children did use one-word utterances in their communication with others, the missing values of MLU and MLLU for these children were given the value 1 . At age $2 \frac{1}{2}$ and 3 years, MLU and MLLU could be calculated from the speech samples for all subjects. Table 3 shows the group means and SD at age 2, 21/2, and 3 years. These data were tested in a simple main effect design with a MANOVA. For MLU, this yielded the following results: at the age of 2 years, there was no significant difference between the two groups in the MLU $\left(\mathrm{F}_{1,10}=2.44 ; p=.15\right)$. When tested 6 months later at $2 \frac{1}{2}$ years of age, the children in the IO group produced higher MLU than the non-IO children. The results were statistically significant: $\mathrm{F}_{1,10}=5.30 ; p=.04$. Finally, at 3 years of age, the IO group continued to produce higher

TABLE 4 Mean Percentile Scores and SD on the Vocabulary Test and on the Test for Sentence Development in Follow-Up at Age 6*

\begin{tabular}{lcccccc}
\hline & \multicolumn{2}{c}{ Vocabulary } & Test & & \multicolumn{2}{c}{ Sentence Development } \\
\cline { 2 - 3 } \cline { 5 - 6 } & Mean & $S D$ & & Mean & $S D$ \\
\hline IO $(\mathrm{n}=6)$ & 81.7 & 19.0 & & 65.8 & 34.4 \\
Non-IO $(\mathrm{n}=5)$ & 61.4 & 32.7 & & 46.2 & 31.8 \\
\hline
\end{tabular}

$* \mathrm{IO}=$ infant orthopedics.
MLU. The difference between the groups on the language measure MLU was again significant: $\mathrm{F}_{1,10}=12.19 ; p<.01$.

Similar results were found for MLLU. The groups did not differ significantly in MLLU $\left(\mathrm{F}_{1,10}=3.12 ; p=.11\right)$ at the age of 2 years. However, at $2 \frac{1}{2}$ years, the MLLU was longer in the IO group than in the non-IO group $\left(\mathrm{F}_{1,10}=7.67 ; p=.02\right)$. At 3 years of age, the $\mathrm{IO}$ group produced significantly longer MLLU than the non-IO group $\left(\mathrm{F}_{1,10}=7.67 ; p=.02\right)$. Examination of the group means also shows that both MLU and MLLU increased with age.

\section{Expressive Vocabulary at 6 Years of Age}

The results of the test for expressive vocabulary are shown in Table 4. All children obtained a score within the normal range. In fact, the means for both groups were above the test norm for 6-year-old children (i.e., percentile score 50). A Student's $t$ test was used to evaluate differences in expressive vocabulary between the two treatment groups. No significant differences were observed between the IO and non-IO group $\left(\mathrm{t}_{9}=1.29 ; p=.23\right)$.

\section{Syntactic Development at 6 Years of Age}

The syntactic development of the children was normal except for one child in the non-IO group who obtained an atrisk score. As a group, the IO children obtained somewhat higher percentile scores than the non-IO group (Table 4), but this difference did not reach statistical significance $\left(\mathrm{t}_{9}=0.98\right.$; $p=.36)$.

\section{Discussion}

The aim of this investigation was to evaluate the effects of IO on language development in children with UCLP. A group of 12 children was followed up longitudinally from 2 to 3 years, and 11 of these children were reassessed in a follow-up evaluation at 6 years of age. There was no significant difference in receptive language skills between the two treatment groups at age $2^{1 / 2}$ and 3 years. In fact, the mean scores of both groups were very close to the test norm. The raw score on the receptive language test significantly increased between the age of $2^{1 / 2}$ and 3 , and treatment with IO did not affect this pattern. When the receptive language skill of each child was considered separately, it appeared that at the ages of $2 \frac{1}{2}$ and 3 years, only one child in each group had receptive language skills that were at risk. It should be noted that although the test was developed and standardized for young children, the 2-year-olds 
in our study could not be tested reliably. This is most likely because of the fact that we tested the children in their home environment. Children are more at ease in this situation and may lose interest in the test at an earlier moment than in a more formal test situation in the clinic.

The expressive syntactic language skills at age 2 to 3 years were reflected in MLU and MLLU measured in number of words. The validity of these measures is discussed by Brown (1973), Beheydt (1983), and Wells (1985). Brown stated that "the MLU is an excellent simple index of grammatical development because almost every new kind of knowledge increases length: the number of semantic roles expressed in a sentence, the addition of obligatory morphemes, coding modulations of meaning, the addition of negative forms and auxiliaries used in interrogative and negative modalities, and, of course, embedding and coordinating" (p. 53). Wells (1985) investigated MLU and MLLU in normally developing children from age 1.3 to 5.0 years and concluded that these measures are suitable indexes of global morphosyntactic development in children below 31/2 years of age. Bol and Kuiken (1988) confirmed that quantitative language measures like MLU and MLLU (in morphemes) increase until age 31/2 years in children with normal language development. Furthermore, it was shown that MLU and MLLU correlate quite highly with more specific linguistic measures of development. Wells (1985) also emphasized the limitations of a global measure such as MLU; it does not discriminate among the various types of linguistic development that give rise to an increase in number of words, and it is insensitive to other types of development that are not manifested in increasing length of utterances. These limitations especially hold for language development in children older than 4 years when mastery of a new linguistic structure such as ellipsis can actually lead to a decrease in MLU.

Beheydt (1983) confirmed that MLU is a simple, reliable, and stable index of syntactic complexity, especially in younger children. He suggested calculating MLU in words and not in morphemes because words rather than morphemes are relevant units in child language. Furthermore, in young children it is often difficult to determine whether suffixes in plurals or in diminutives are used as morphemes. In early stages of language development, the child may use these suffixes without meaning, i.e., without opposition to the singular form of the noun (Moerman-Coetsier and Van Besien, 1987). Consequently, calculation of MLU in words is less complicated and more reliable. In addition, Moerman-Coetsier and Van Besien demonstrated that there is a strong correlation between MLU in words and MLU in morphemes $(r=0.98)$ in young children aged $2 \frac{1}{2}$ to 3 years. Their findings correspond to results of Arlman-Rupp et al. (1976). Nevertheless, Moerman-Coetsier and Van Besien (1987) argue for cautious use of MLU as a measure for syntactic capacities of the child. MLU is easily influenced by the nature of the interactions with the child. For example, closed questions lead to shorter MLU than open questions. This does not hold for very young children who, because of their limited syntactic knowledge, are not able to produce sentences longer than two words regardless of the nature of the stimulus that is introduced.

The results of the MLU and MLLU measures in our study showed that at the age of 2 years, the two treatment groups did not differ from each other with regard to the mean length of utterance. In contrast, at the ages of $2 \frac{1}{2}$ and 3 years, the children in the IO group produced longer utterances than the children in the non-IO group. Remarkably, the difference in utterance length did not manifest itself until the age of $2 \frac{1}{2}$ years. The absence of significant differences at the younger age is consistent with the results of Jocelyn et al. (1996), who also found no significant differences in MLU between children with CLP and noncleft controls at 12 and 24 months. The delayed effect that we found may be the result of better interaction with and feedback from the child's environment. Earlier results from this clinical trial have shown that the IO group appears to benefit from the treatment by achieving more normal speech development at an early stage. Children treated with IO use more alveolar consonantlike sounds in their babbling (Konst et al., 1999), and they follow a more normal path of phonological development (Konst et al., 2002). Children with a more normal speech development may be better understood by their environment and, as a consequence, may receive better and more adequate feedback, which may facilitate their language development.

In the follow-up at 6 years, the two groups no longer differed in expressive syntactic skills. Although the children who were not treated with IO experienced a language delay in the period around their third year, they managed to catch up with the children in the IO group and with the norm group at some stage between the age of 3 and 6 years. The syntactic development of one of our 6-year-old subjects (non-IO) was still at risk at the time of testing. The child continued to receive special education for children with severe speech and language delays.

Similarly, there were no significant differences in expressive vocabulary between the two groups of children with UCLP. In fact, the mean percentile scores for both groups were above the test norm (percentile 50). The above-average performance of the subjects cannot be explained by SES, which was low for four families, middle class for five families, and high for two families. Enhanced expressive vocabulary may be at least partially explained by the fact that all subjects received speech therapy for a period of time between the ages of 3 and 6 years.

Overall, the language delay in the children in this study was transient. Many of the expressive language delays reported in other studies are transient as well (Broen et al., 1998). It should be noted, however, that the participants in our study were children with UCLP. The results may be quite different in children with other types of cleft because it has been reported that children with CPO still exhibited language delays in their school age (Richman and Eliason, 1984).

Although our results showed a temporary positive effect of IO on language development, the value of IO cannot be judged on these results alone. Other outcome variables such as maxillary arch dimensions, facial and dental appearances, cost-ef- 
fectiveness, and long-term follow-up should be taken into account when considering the comprehensive effect of IO.

Acknowledgments. The authors express their gratitude to the cleft palate centers of Nijmegen, Amsterdam, and Rotterdam with special thanks to the speech pathologists and the ENT specialists. We are also indebted to Hanny WeersinkBraks and Katja Bongaarts for their help in collecting the data.

\section{REFERENCES}

Arlman-Rupp AJL, Van Niekerk de Haan D, Van de Sandt-Koenderman M. Brown's early stages: some evidence from Dutch. J Child Lang. 1976;3: 267-274.

Beheydt L. Kindertaalonderzoek, een Methodologisch Handboek. Louvain-laNeuve: Cabay; 1983.

Bol GW, Kuiken F. Grammaticale Analyse van Taalontwikkelingsstoornissen. Utrecht: Elinkwijk BV; 1988.

Broder HL, Richman LC, Matheson PB. Learning disability, school achievement, and grade retention among children with cleft: a two-center study. Cleft Palate Craniofac J. 1998;35:127-131.

Broen PA, Devers M, Doyle SS, McCauly Prouty J, Moller KT. Aquisition of linguistic and cognitive skills by children with cleft palate. J Speech Lang Hear Res. 1998;41:676-687.

Broen PA, Moller KT, Carlstrom J, Doyle SS, Devers M, Keenan KM. Comparison of the hearing histories of children with and without cleft palate. Cleft Palate Craniofac J. 1996;33:127-133.

Brown R. A First Language: The Early Stages. London: George Allen and Unwin Ltd; 1973.

Čeponiené R, Hukki J, Cheour M, Haapanen M-L, Ranta R, Näätänen R. Cortical auditory dysfunction in children with oral clefts: relation with cleft type. Clin Neurophysiol. 1999;110:1921-1926.

Chapman KL, Graham K, Gooch J, Visconti C. Conversational skills of preschool and school-age children with cleft lip and palate. Cleft Palate Craniofac J. 1998;35:503-516.

Chapman KL, Hardin MA. Language input of mothers interacting with their young children with cleft lip and palate. Cleft Palate Craniofac J. 1991;28: $78-85$.

Eliason MJ, Richman LC. Language development in preschoolers with cleft. Dev Neuropsychol. 1990;6:173-182.

Feagans L, Sanyal M, Henderson F, Collier A, Appelbaum M. Relationship of middle ear disease in early childhood to later narrative and attentional skills. J Pediatr Psychol. 1987;12:581-594.

Friel-Patti S, Finitzo T. Language learning in a prospective study of otitis media with effusion in the first two years of life. J Speech Lang Hear Res. 1990; 33:188-194.

Gnoinski W. Infant orthopedics and later orthodontic monitoring for unilateral cleft lip and palate patients in Zurich. In: Bardach J, Morris HL, eds. Multidisciplinary Management of Cleft Lip and Palate. Philadelphia: WB Saunders; 1990:578-585.

Gravel JS, Wallace IF. Listening and language at 4 years of age: effects of early otitis media. J Speech Hear Res. 1992;35:588-595.

Gruber H. Presurgical maxillary orthopedics. In: Bardach J, Morris HL, eds. Multidisciplinary Treatment of Cleft Lip and Palate. Philadelphia: WB Saunders; 1990:592-600.

Hotz M, Gnoinski W, Perko M, Nussbaumer H, Hof E, Haubensak R. The Zurich approach, 1964 to 1984. In: Hotz M, Gnoinski W, Perko M, Nussbaumer H, Hof E, Haubensak R, eds. Early Treatment of Cleft Lip and Palate. Toronto: Hans Huber Publishers; 1986:42-48.
Jocelyn LJ, Penko MA, Rode HL. Cognition, communication, and hearing in young children with cleft lip and palate and in control children: a longitudinal study. Pediatrics. 1996;97:529-534.

Konst EM, Rietveld T, Peters H, Prahl-Andersen B. Phonological development of toddlers with unilateral cleft lip and palate who were treated with and without infant orthopedics: a randomized clinical trial. Cleft Palate Craniofac J. 2003;40:32-39.

Konst EM, Weersink-Braks H, Rietveld T, Peters H. An intelligibility assessment of toddlers with cleft lip and palate who received and did not receive presurgical infant orthopedic treatment. J Coтmиn Disord. 2000;33:483501.

Konst EM, Weersink-Braks H, Rietveld T, Peters HFM. Prelexical development of unilateral cleft lip and palate babies with reference to presurgical infant orthopaedics: a randomized prospective clinical trial. Clin Linguist Phon. 1999;13:395-407.

Moerman-Coetsier L, van Besien F. TOAST: Taalonderzoek via Analyse van Spontane Taal. Leuven/Amersfoort: Acco; 1987.

Neiman GS, Savage HE. Development of infants and toddlers with clefts from birth to three years. Cleft Palate Craniofac J. 1997;34:218-225.

Paul R, Lynn TF, Lohr-Flanders M. History of middle ear involvement and speech/language development in late talkers. J Speech Hear Res. 1993;36: 1055-1062.

Prahl C, Kuijpers-Jagtman AM, van't Hof MA, Prahl-Andersen B. A randomised prospective clinical trial into the effects of infant orthopaedics on maxillary arch dimensions in unilateral cleft lip and palate (Dutchcleft). Eur $J$ Oral Sci. 2001;109:297-305.

Richman LC, Eliason MJ. Type of reading disability related to cleft type and neuropsychological patterns. Cleft Palate J. 1984;21:1-6.

Roberts JE, Burchinal MR, Davis BP, Collier AM, Henderson FW. Otitis media in early childhood and later language. J Speech Hear Res. 1991;34:11581168.

Roberts JE, Burchinal MR, Medley L, Zeisel SA, Mundy M, Roush J, Hooper S, Bryant D, Henderson FW. Otitis media, hearing sensitivity, and maternal responsiveness in relation to language during infancy. J Pediatr. 1995;126: 481-489.

Schaerlaekens A, van Ommeslaeghe K. Reynell Taalontwikkelingsschalen, Handleiding. Nijmegen: Berkhout BV; 1993.

Schlichting JEPT, van Eldik MCM, Lutje Spelberg HC, van der Meulen, S, van der Meulen, BF. Schlichting Test voor Taalproductie. Nijmegen: Berkhout Nijmegen BV; 1995.

Shriberg LD, Flipsen P, Thielke H, Kwiatkowski J, Kertoy MK, Katcher ML, Nellis RA, Block MG. Risk for speech disorder associated with early recurrent otitis media with effusion: two retrospective studies. J Speech Lang Hear Res. 2000a;43:79-99.

Shriberg LD, Friel-Patti S, Flipsen P, Brown RL. Otitis media, fluctuant hearing loss, and speech-language outcomes: a preliminary structural equation model. J Speech Lang Hear Res. 2000b;43:100-120.

Stuffins GM. Speech and mental attitudes in the older presurgical child. In: Kehrer B, Slingo T, Graf B, Bettex M, eds. Long Term Treatment in Cleft Lip and Palate. Proceedings of the First International Symposium. Bern: Hans Huber Publishers; 1981:199-206.

Van Bon WHJ. Taaltests voor Kinderen. Lisse: Swets and Zeitlinger BV; 1982.

Van Westerlaak J, Kropman W, Collaris J. Beroepenklapper. Nijmegen: Instituut voor Toegepaste Sociologie; 1975.

Wasserman GA, Allen R, Linares LO. Maternal interaction and language development in children with and without speech-related anomalies. J Commun Disord. 1988;21:319-331.

Wells G. Language Development in the Pre-School Years. Cambridge: Cambridge University Press; 1985. 